\title{
$\mathrm{SC}$

OPEN Data Descriptor: De novo \section{transcriptome assembly of fluorine accumulator tea plant Camellia sinensis with fluoride treatments}

Received: 13 February 2018

Accepted: 3 August 2018

Published: 25 September 2018

\section{Qing-Sheng $\mathrm{Li}^{1}$, Xu-Min $\mathrm{Li}^{1}$, Ru-Ying Qiao ${ }^{2}$, En-Hui Shen ${ }^{3}$, Xiao-Ming $\mathrm{Lin}^{1}$, Jian-Liang Lu ${ }^{1}$, Jian-Hui Ye ${ }^{1}$, Yue-Rong Liang ${ }^{1} \&$ Xin-Qiang Zheng ${ }^{1}$}

Tea plant (Camellia sinensis) is a typical fluoride (F) hyperaccumulator enriching most $\mathrm{F}$ in old leaves. There is association between the risk of fluorosis and excessive consumption of teas prepared using the old leaves. It is meaningful to develop methods for controlling $\mathrm{F}$ levels in tea leaves. We generated a comprehensive RNA-seq dataset from tea plants grown at various $F$ levels for different durations by hydroponics, aiming at providing information on mechanism of $\mathrm{F}$ metabolism in tea plant. Besides raw reads of the RNA-seq dataset, we present assembled unigenes and aligned unigenes with annotations versus the Gene Ontology (GO) databases, Kyoto Encyclopaedia of Genes and Genomes (KEGG) databases, and Nonredundant (Nr) protein databases with low e-values. 69,488 unigenes were obtained in total, in which 40,894 were given $\mathrm{Nr}$ annotations.

\begin{tabular}{|c|c|}
\hline Design Type(s) & $\begin{array}{l}\text { transcription profiling by high throughput sequencing design - factorial design } \\
\text { - sequence assembly objective }\end{array}$ \\
\hline Measurement Type(s) & transcription profiling assay \\
\hline Technology Type(s) & RNA sequencing \\
\hline Factor Type(s) & Fluoride Measurement $•$ Experimental Condition $•$ Exposure Duration \\
\hline Sample & C \\
\hline
\end{tabular}

\footnotetext{
${ }^{1}$ Tea Research Institute, College of Agriculture and Biotechnology, Zhejiang University, Hangzhou, 310058, China. ${ }^{2}$ Tea Department, Wuzhou University, Wuzhou, 543000, China. ${ }^{3}$ Institute of Crop Science \& Institute of Bioinformatics, College of Agriculture and Biotechnology, Zhejiang University, Hangzhou, 310058, China. Correspondence and requests for materials should be addressed to Y.R.L. (email: yrliang@zju.edu.cn) or X.Q.Z. (email: xqzheng@zju.edu.cn)
} 


\section{Background \& Summary}

Tea plants accumulate abundant fluoride (F) from environments without toxicity ${ }^{1-3}$. The $\mathrm{F}$ concentration in mature tea leaves was up to $2800 \mathrm{mg} / \mathrm{kg}^{4}$. In general, tea brewing leaches $24-83 \%$ of total $\mathrm{F}$ into infusions ${ }^{4}$. An adult drinking five cups of tea per day would intake $8.0-303 \% \mathrm{~F}$ content of the Polish SAI (Safe and Adequate Daily Intake) ${ }^{5}$. Long-term consumption of brick teas with excess F would increase the risk of dental and skeletal fluorosis ${ }^{6,7}$.

Fluoride uptake by tea plant is highly related to $\mathrm{Al}, \mathrm{Ca}$ and anion channels. Adding $\mathrm{Al}$ to the soil or hydroponic solution increased $\mathrm{F}$ accumulation in tea plant but had no effect on $\mathrm{Al}$ accumulation ${ }^{8}$. Tea plant might absorb $\mathrm{F}$ through a F-Al complex ${ }^{9}$. Endogenous $\mathrm{Ca}^{2+}$ and CaM played an important role in $\mathrm{F}$ accumulation when there was $\mathrm{Al}^{3+}$ in the hydroponic solution ${ }^{10}$. The addition of $\mathrm{Ca}^{2+}$ decreased the passages in cell wall or membrane, resulting in reduction of $\mathrm{F}$ uptake ${ }^{11}$. F uptake by tea plants was related to anion channel, because anionic channel inhibitor NPPB or DIDS could reduce F absorption ${ }^{12}$.

For non-model organisms with limited information of genome, ribonucleic acid sequencing (RNASeq) is an efficient approach to transcriptome profiling ${ }^{13-15}$. In this study, RNA-Seq was tested on tea leaf samples from hydroponic tea plants grown at three levels of $\mathrm{F}$ for two growing duration, with two biological replicates and control. Based on $10 \mathrm{cDNA}$ libraries, a de novo assembled transcriptome was generated using all $\mathrm{F}$ treatments and control samples. After de novo assembly, total 69,488 unigenes were obtained with N50 of $869 \mathrm{bp}$. The unigene dataset can help explore the potential genes towards F metabolism in tea plant.

\section{Methods \\ Experiment design}

Two-year-old tea cuttings of Camellia sinensis cv. 'JK2' were cultured by hydroponic method in a climate chamber at $25 \pm 2{ }^{\circ} \mathrm{C}, 70 \pm 10 \%$ relative humidity and $12 \mathrm{~h} \mathrm{light} / 12 \mathrm{~h}$ dark ${ }^{16}$. The nutrient solution was renewed weekly with formula as below: $100.05 \mathrm{mg} / \mathrm{L} \mathrm{NH}_{4} \mathrm{NO}_{3}, 34.68 \mathrm{mg} / \mathrm{L} \mathrm{KH}_{2} \mathrm{PO}_{4}, 1.64 \mathrm{mg} / \mathrm{L} \mathrm{K} \mathrm{HPO}_{4}$, $2.15 \mathrm{mg} / \mathrm{L} \quad \mathrm{CaSO}_{4} \cdot 2 \mathrm{H}_{2} \mathrm{O}, \quad 49.00 \mathrm{mg} / \mathrm{L} \mathrm{MgSO}{ }_{4} \cdot 7 \mathrm{H}_{2} \mathrm{O}, 33.32 \mathrm{mg} / \mathrm{L} \quad \mathrm{Al}_{2}\left(\mathrm{SO}_{4}\right)_{3} \cdot 10 \mathrm{H}_{2} \mathrm{O}, 0.28 \mathrm{mg} / \mathrm{L} \quad \mathrm{FeS}-$ $\mathrm{O}_{4} \cdot 7 \mathrm{H}_{2} \mathrm{O}, 14.21 \mathrm{mg} / \mathrm{L} \mathrm{Na} \mathrm{SiO}_{3} \cdot 9 \mathrm{H}_{2} \mathrm{O}, 5.00 \mathrm{mg} / \mathrm{L} \mathrm{H}_{3} \mathrm{BO}_{3}, 3.00 \mathrm{mg} / \mathrm{L} \mathrm{MnSO}_{4}, 0.44 \mathrm{mg} / \mathrm{L} \mathrm{ZnSO} \cdot 7 \mathrm{H}_{2} \mathrm{O}$, $0.16 \mathrm{mg} / \mathrm{L} \mathrm{CuSO} \cdot 5 \mathrm{H}_{2} \mathrm{O}, 0.16 \mathrm{mg} / \mathrm{L} \mathrm{Na}_{2} \mathrm{MoO}_{4} \cdot 2 \mathrm{H}_{2} \mathrm{O}$, and the $\mathrm{pH}$ of the solution was adjusted to $4.8-5.2$ by $0.1 \mathrm{~mol} / \mathrm{L} \mathrm{HCl}$ or $0.1 \mathrm{~mol} / \mathrm{L} \mathrm{NaOH}^{16}$. After eight weeks acclimation in the nutrient solution, the tea plants were treated with three levels of $\mathrm{F}(0,5,20 \mathrm{mg} / \mathrm{L})$. Third leaf from apical bud with biological replicates were sampled for $\mathrm{F}$ content analysis and RNA extraction on the day before $\mathrm{F}$ treatment using 0 $\mathrm{mg} / \mathrm{L}$ group as control, and $5 \mathrm{mg} / \mathrm{L}, 20 \mathrm{mg} / \mathrm{L}$ combined with $1^{\text {st }}, 3^{\text {rd }}$ day as treatment groups. The labels of $\mathrm{F}$ treatment were as below, sampling before $\mathrm{F}$ treatment from $0 \mathrm{mg} / \mathrm{L}$ F group was used as control (tabbed as Ftea-CK), $5 \mathrm{mg} / \mathrm{L}$ F for 1 day (tabbed as Ftea-S5-1), $5 \mathrm{mg} / \mathrm{L} \mathrm{F}$ for 3 days (tabbed as Ftea-S5-3), $20 \mathrm{mg} / \mathrm{L}$ F for 1 day (tabbed as Ftea-S20-1), $20 \mathrm{mg} / \mathrm{L}$ F for 3 days (tabbed as Ftea-S20-3). The experiment design and the sampling standard were illustrated in Fig. 1.

\section{Fluoride determination}

F contents in tea samples were determined using F ion selective electrode (Shanghai Ruosull Technology Co., Ltd., Shanghai China) mainly following the method described by Stevens et al. ${ }^{17}$. To inactivate enzymes in tea leaves, we added a pretreatment of $\mathrm{F}$ determination by microwaving tea leaves for $60 \mathrm{~s}$. Then the leaves were dried at $120^{\circ} \mathrm{C}$ for $30 \mathrm{~min}$ and at $75^{\circ} \mathrm{C}$ for $3 \mathrm{~h}$ to $48 \mathrm{~h}$ until the weights of the leaves remained unchanged. Dry samples $(0.15 \mathrm{~g})$ were accurately measured into conical flasks with $20 \mathrm{~mL}$ boiling water for $30 \mathrm{~min}$ and shook up per $10 \mathrm{~min}$. Then the solutions were transferred into $50 \mathrm{~mL}$ volumetric flask with TISAB solution $(3 \mathrm{~mol} / \mathrm{L}$ sodium acetate: $0.75 \mathrm{~mol} / \mathrm{L}$ sodium citrate $=1: 1 \mathrm{v} / \mathrm{v}$ ) and metered the solution to $50 \mathrm{~mL}$ with $\mathrm{ddH}_{2} \mathrm{O}$. Each solution was measured by $\mathrm{F}$ ion selective electrode until the change in $\mathrm{mV}$ was less than $0.2 \mathrm{mV} / \mathrm{min}$. The standard curve was constructed by $\mathrm{NaF}$ (AR grade, dried at $105^{\circ} \mathrm{C}$ for $2 \mathrm{~h}$ ). All $\mathrm{F}$ concentrations of samples were calculated by direct calibration from the standard curve. The reclaim rate of the added $\mathrm{F}$ was $95.0-99.3 \%$, with coefficient of variation $2.1 \%$. The results of $\mathrm{F}$ contents in different tea samples were listed in Table 1.

\section{RNA extraction}

Total RNA was extracted using an RNAprep pure plant kit special for plants with high content of polysaccharide or polyphenols (TIANGEN Biotech Co., Ltd., Beijing, China). The quality and quantity of extracted RNA were measured by agarose gel electrophoresis and Nanodrop 2000 (Quawell Technology, Inc., San Jose, USA). The extracted RNA samples were stored at $-80^{\circ} \mathrm{C}$.

\section{Library construction and transcriptome sequencing}

Three $\mu \mathrm{g}$ total RNA of each sample was used for cDNA library construction using TruSeq Stranded mRNA LT Sample Prep Kit (Illumina, San Diego, CA, USA). The mRNA was extracted from total RNA by oligo (dT)-attached magnetic beads. A cDNA library was generated before Next-Generation Sequencing (NGS) in five steps: (1) The mRNA was fragmented using divalent cations under elevated temperature in an Illumina proprietary fragmentation buffer, with mRNA fragment length ranging from 200 to $300 \mathrm{bp}$; (2) First-strand cDNA was synthesized by random oligonucleotides and SuperScript II using the mRNA fragments as template. (3) Second-strand cDNA was synthesized in a mixture of buffer, 


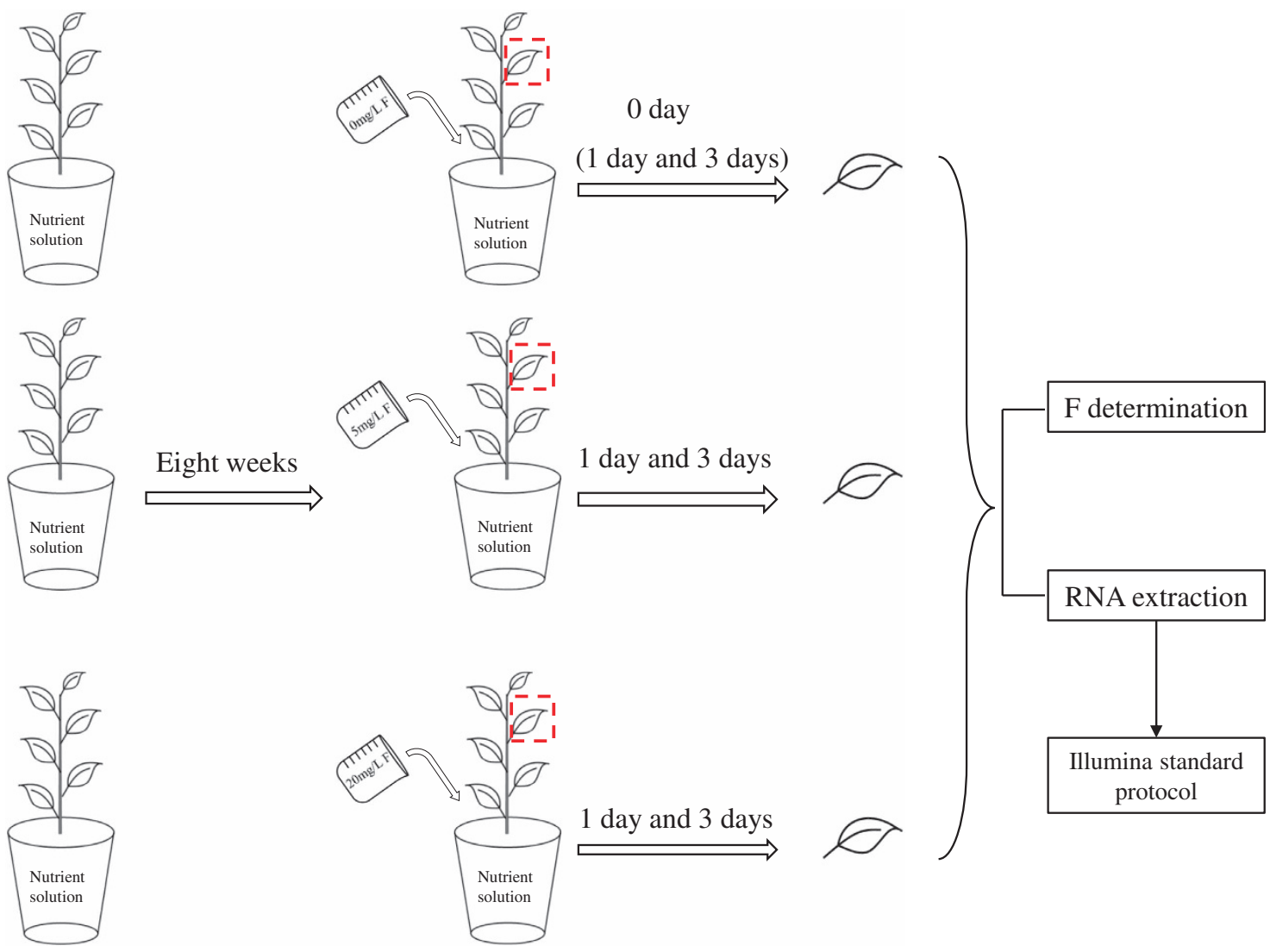

Figure 1. Experiment design and sampling standard. Sampling on 0 day under $0 \mathrm{mg} / \mathrm{L} \mathrm{F}$ treatment was used as control (tabbed as Ftea-CK), and sampling on 1 and 3 days under $0 \mathrm{mg} / \mathrm{L} \mathrm{F}$ treatment were used for $\mathrm{F}$ determination; Ftea-S5-1: 5 mg/L F treatment for 1 day; Ftea-S5-3: 5 mg/L F treatment for 3 days; Ftea-S20-1: $20 \mathrm{mg} / \mathrm{L} \mathrm{F}$ treatment for 1 day; Ftea-S20-3: $20 \mathrm{mg} / \mathrm{L} \mathrm{F}$ treatment for 3 days. F levels in all samples were measured and the de novo assembled transcriptome was based on Ftea-CK, Ftea-S5-1, Ftea-S5-3, Ftea-S20-1, and Ftea-S20-3 with biological replicates.

\begin{tabular}{|l|l|l|l|}
\hline \multirow{2}{*}{ Time (d) } & \multicolumn{3}{|c|}{ F level (mg/kg) } \\
\cline { 2 - 4 } & Ftea-CK & Ftea-S5 & Ftea-S20 \\
\hline 1 & $180.6 \pm 1.3$ & $265.5 \pm 4.5$ & $305.4 \pm 3.5$ \\
\hline 3 & $179.4 \pm 1.2$ & $376.7 \pm 2.4$ & $513.3 \pm 4.2$ \\
\hline
\end{tabular}

Table 1. The results of fluoride treatment on $\mathbf{F}$ levels in tea leaves. Time (d): F treating duration on tea cuttings. F level (mg/kg): F contents in tea samples. Ftea-CK: tea cuttings under $0 \mathrm{mg} / \mathrm{L} \mathrm{F}$ concentration in hydroponic solutions. Ftea-S5: tea cuttings under $5 \mathrm{mg} / \mathrm{L} \mathrm{F}$ concentration in hydroponic solutions. Ftea-S20: tea cuttings under $20 \mathrm{mg} / \mathrm{L} \mathrm{F}$ concentration in hydroponic solutions.

dNTPs, RNase H, and DNA polymerase I, in which thymine (T) was replaced by uracil (U) so as to generate strand-specific library. (4) DNA fragments with ligated adaptor molecules on both ends were selectively enriched using Illumina PCR Primer Cocktail in a 15 cycle PCR reaction. After PCR amplification of the cDNA library, the libraries between 300-400 bp were chosen for next step. (5) Products were purified (AMPure XP system) and quantified using the Agilent high sensitivity DNA assay on a Bioanalyzer 2100 system (Agilent). Finally, Illumina NextSeq500 was performed to generate $2 \times 150$ bp paired-end (PE) reads. The major process of the study was listed in Fig. 2.

\section{De novo assembly and annotation}

Before assembly, the reads with low quality were removed and adapters were filtered with Cutadapt (Version 1.2.1 ${ }^{18}$. Clean reads were pooled and RNA-Seq de novo assembly was carried out using Trinity, including assembling the reads into contigs by Inchworm, clustering the contigs to generate De Brujin 


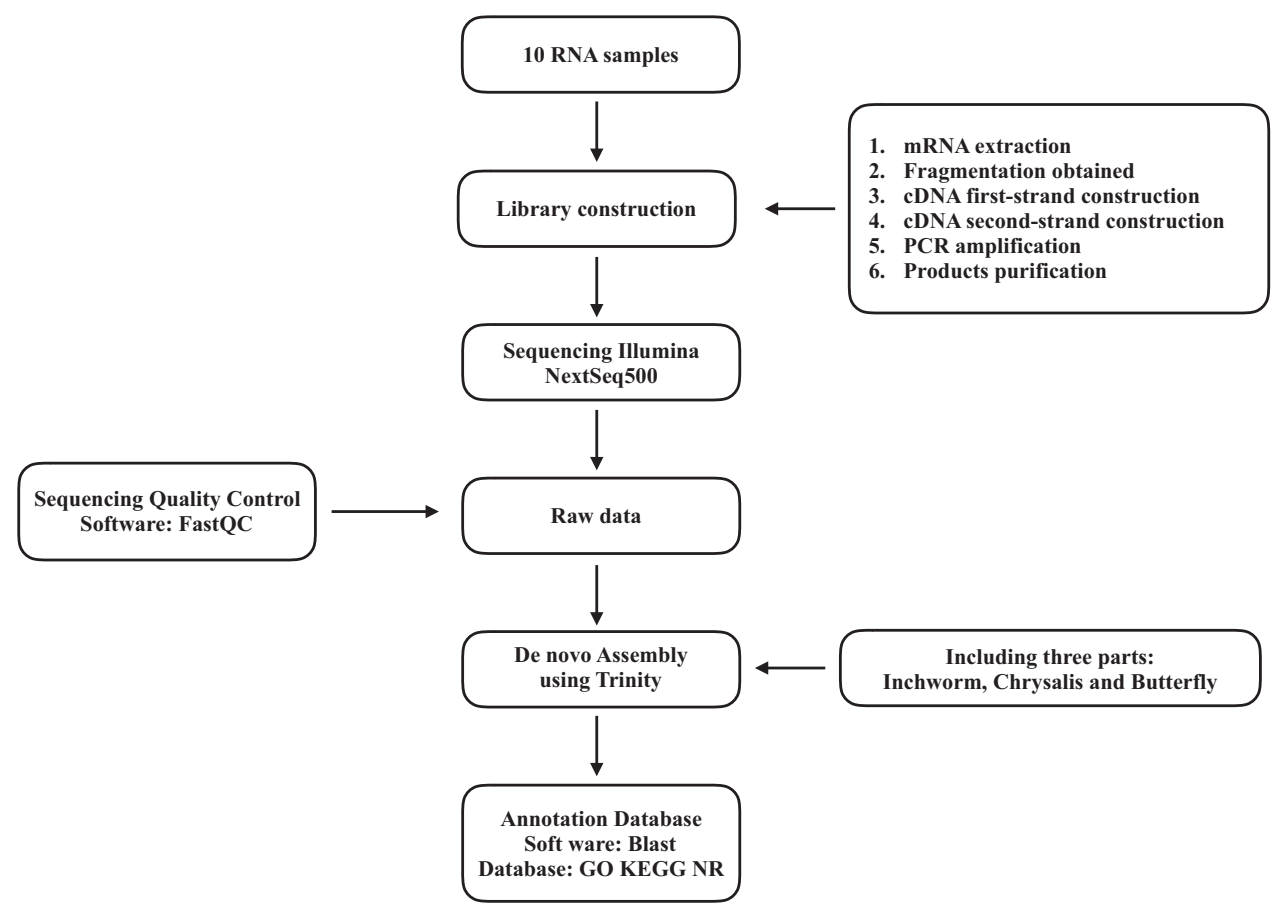

Figure 2. Schematic overview of the study. We collected 5 samples with replicates (third leaf from bud) including control and various fluoride treatments. After cDNA construction, Illumina NextSeq500 was used for sequencing in 150 bp paired-end (PE) reads. Trinity was used for clean reads de novo assembly and BlastX was used searching against GO, KEGG and NR databases.

\begin{tabular}{|l|l|l|}
\hline & Contig & \multicolumn{1}{|c|}{ Unigene } \\
\hline Total Length (bp) & $66,634,674$ & $40,814,856$ \\
\hline Sequence Number & 219,018 & 69,488 \\
\hline Max. Length (bp) & 7,149 & 6,325 \\
\hline Mean Length (bp) & 304.2 & 587.4 \\
\hline N50 (bp) & 412 & 869 \\
\hline N50 Sequence No. & 35,411 & 13,326 \\
\hline N90 (bp) & 131 & 250 \\
\hline N90 Sequence No. & 160,691 & 51,233 \\
\hline GC\% & 45.36 & 43.75 \\
\hline
\end{tabular}

Table 2. Summary of contigs and unigenes. Total Length (bp): the sum length of all contigs or unigenes. Sequence Number: the number of assembled contigs or unigenes. Max length: the length of longest contig or unigene. Mean length: the average length of contigs or unigenes. N50 (bp): arranging all sequences from longest to shortest, then adding the sequences with permutation. When the sum of the sequences reaches to $50 \%$ of total length, the length of last sequence is N50 (bp). N50 Sequence NO: the number of sequences longer than N50. N90 (bp): arranging all sequences from longest to shortest, then adding the sequences with permutation. When the sum of the sequences reaches to $90 \%$ of total length, the length of last sequence is N90 (bp). N90 Sequence NO: the number of sequences longer than N90. GC\%: the percentage of GC in all bases.

Graph (DBG) by Chrysalis, and obtaining transcripts based on $\mathrm{DBG}^{19}$. The fixed default $K$-mer value was 25. Details of contigs and unigenes were listed in Table 2. The obtained unigenes were annotated by conducting a local BLASTx search. To classify the functions of contigs, GO annotation was performed using Blast2GO software ${ }^{20}$, and KEGG orthology and pathway annotations were obtained by KAAS (KEGG Automatic Annotation Server). These methods are expanded versions of descriptions in our related work ${ }^{16}$. 


\begin{tabular}{|l|l|l|l|}
\hline Sample No & Accession & SRA & BioSample \\
\hline 1 & Ftea-CK rep1 & SRR6189369 & SAMN07811449 \\
\hline 2 & Ftea-CK rep2 & SRR6189370 & SAMN07811450 \\
\hline 3 & Ftea-S5-1 rep1 & SRR6189371 & SAMN07811451 \\
\hline 4 & Ftea-S5-1 rep2 & SRR6189372 & SAMN07811453 \\
\hline 5 & Ftea-S5-3 rep1 & SRR6189365 & SAMN07811454 \\
\hline 6 & Ftea-S5-3 rep2 & SRR6189366 & SAMN07811455 \\
\hline 7 & Ftea-S20-1 rep1 & SRR6189367 & SAMN07811456 \\
\hline 8 & Ftea-S20-1 rep2 & SRR6189368 & SAMN07811457 \\
\hline 9 & Ftea-S20-3 rep1 & SRR6189373 & SAMN07811458 \\
\hline 10 & Ftea-S20-3 rep2 & SRR6189374 & \\
\hline
\end{tabular}

Table 3. Summary of samples submitted to NCBI Sequence Read Archive. Ftea-CK: sampling before F treatment from $0 \mathrm{mg} / \mathrm{L}$ group and used as control; Ftea-S5-1: $5 \mathrm{mg} / \mathrm{L}$ F treatment for 1 day; Ftea-S5-3: 5 mg/L F treatment for 3 days; Ftea-S20-1: $20 \mathrm{mg} / \mathrm{L}$ F treatment for 1 day; Ftea-S20-3: $20 \mathrm{mg} / \mathrm{L} \mathrm{F}$ treatment for 3 days. Rep 1 and rep 2 means biological replicates.

\begin{tabular}{|l|l|l|l|}
\hline Sample & Raw Reads & Clean Reads & Clean Reads\% \\
\hline Ftea-CK rep1 & $22,498,116$ & $22,353,496$ & $99.36 \%$ \\
\hline Ftea-CK rep2 & $28,105,672$ & $27,917,452$ & $99.33 \%$ \\
\hline Ftea-S5-1 rep1 & $23,992,856$ & $23,827,212$ & $99.31 \%$ \\
\hline Ftea-S5-1 rep2 & $31,759,734$ & $31,547,722$ & $99.33 \%$ \\
\hline Ftea-S5-3 rep1 & $25,744,530$ & $25,570,978$ & $99.33 \%$ \\
\hline Ftea-S5-3 rep2 & $27,129,926$ & $26,954,244$ & $99.35 \%$ \\
\hline Ftea-S20-1 rep1 & $25,418,168$ & $25,249,726$ & $99.34 \%$ \\
\hline Ftea-S20-1 rep2 & $31,876,778$ & $31,667,652$ & $99.34 \%$ \\
\hline Ftea-S20-3 rep1 & $26,754,336$ & $26,564,954$ & $99.29 \%$ \\
\hline Ftea-S20-3 rep2 & $27,293,256$ & $27,113,294$ & $99.34 \%$ \\
\hline Total & $270,573,372$ & $268,766,730$ & $99.33 \%$ \\
\hline
\end{tabular}

Table 4. Raw data and clean reads for each accession. Raw Reads: reads from next-generation sequencer. Clean Reads: high quality reads after eliminating contaminations and adaptors. Clean Reads\%: the percentage of clean reads.

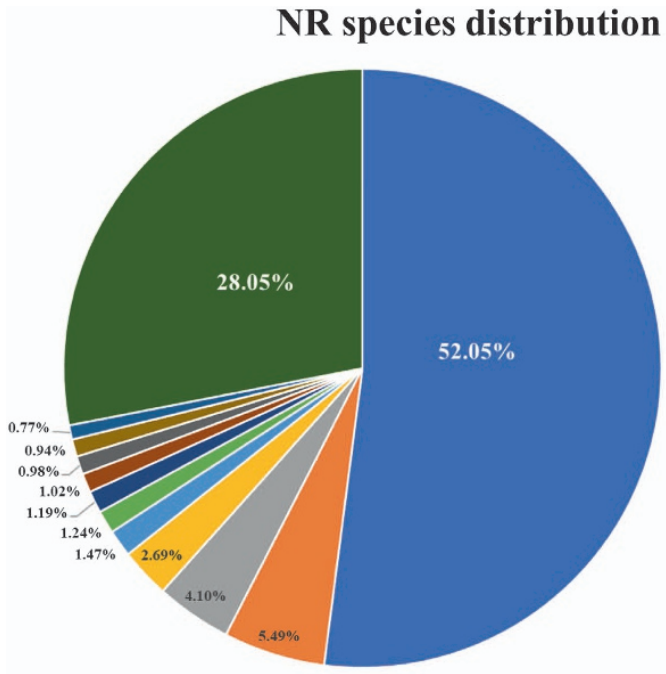

- Actinidia chinensis var. chinensi

- Vitis vinifera

- Quercus suber

Camellia sinensis

- Juglans regia

- Olea europaea var. sylvestris

- Coffea canephora

- Nelumbo nucifera

- Hevea brasiliensis

- Theobroma cacao

- Sesamum indicum

- other

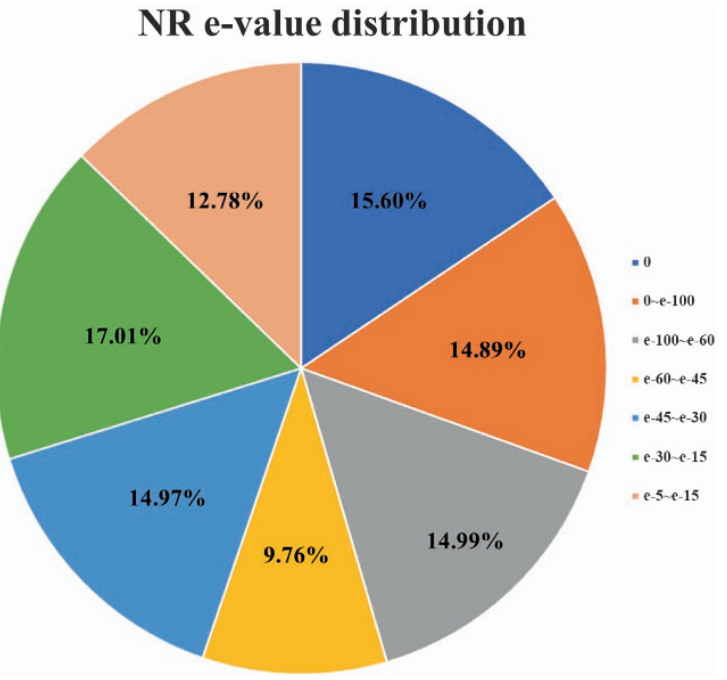

Figure 3. Distribution of NR e-value and species. 


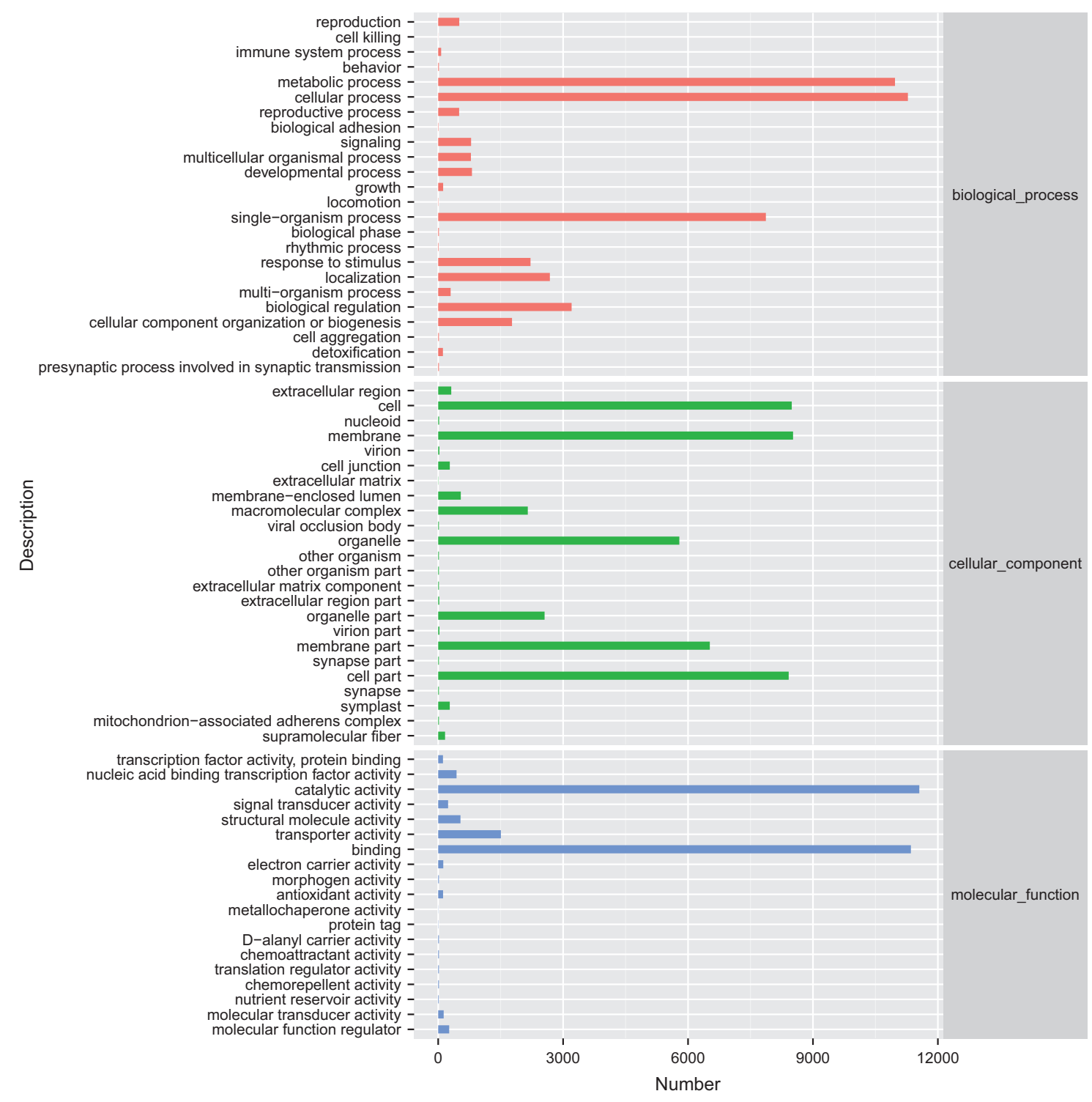

Figure 4. GO functional annotations of Camellia sinensis transcriptome. Bars represent the numbers of unigenes assigned into GO sub-categories of three main categories: biological process, cellular component and molecular function. Within the biological process category, "cellular process", "metabolic process", and "singleorganism process" were the most abundant sub-categories. In cellular component category, the predominant portion of unigenes represented "membrane", "cell" and "cell part" followed by "membrane part" and "organelle". Under the molecular function category, "catalytic activity" and "binding" sub-categories were the major proportions of unigenes.

\section{Data Records}

The raw data (Data Citation 1 and Table 3) was deposited in the NCBI Sequence Read Archive. Each accession has two replicates. The assembled unigenes have been deposited at GenBank (Data Citation 2).

\section{Technical Validation}

To first control the sequencing quality, we compared total reads and total bases of each sample to ensure the amounts stood the same magnitude. The Q20, base content, GC content and sequence base quality were then determined using FastQC (http://www.bioinformatics.babraham.ac.uk/projects/fastqc). In order to comprehensively cover the transcriptome of Camellia sinensis, ten libraries of control and experimental groups were sequenced and assembled. A total of 270573372 raw reads were generated. 268766730 clean reads were obtained for de novo assembly after filtration, with clean reads rate being up to $99.33 \%$ (Table 4). 219018 contigs and 69488 unigenes were obtained (Table 2). 


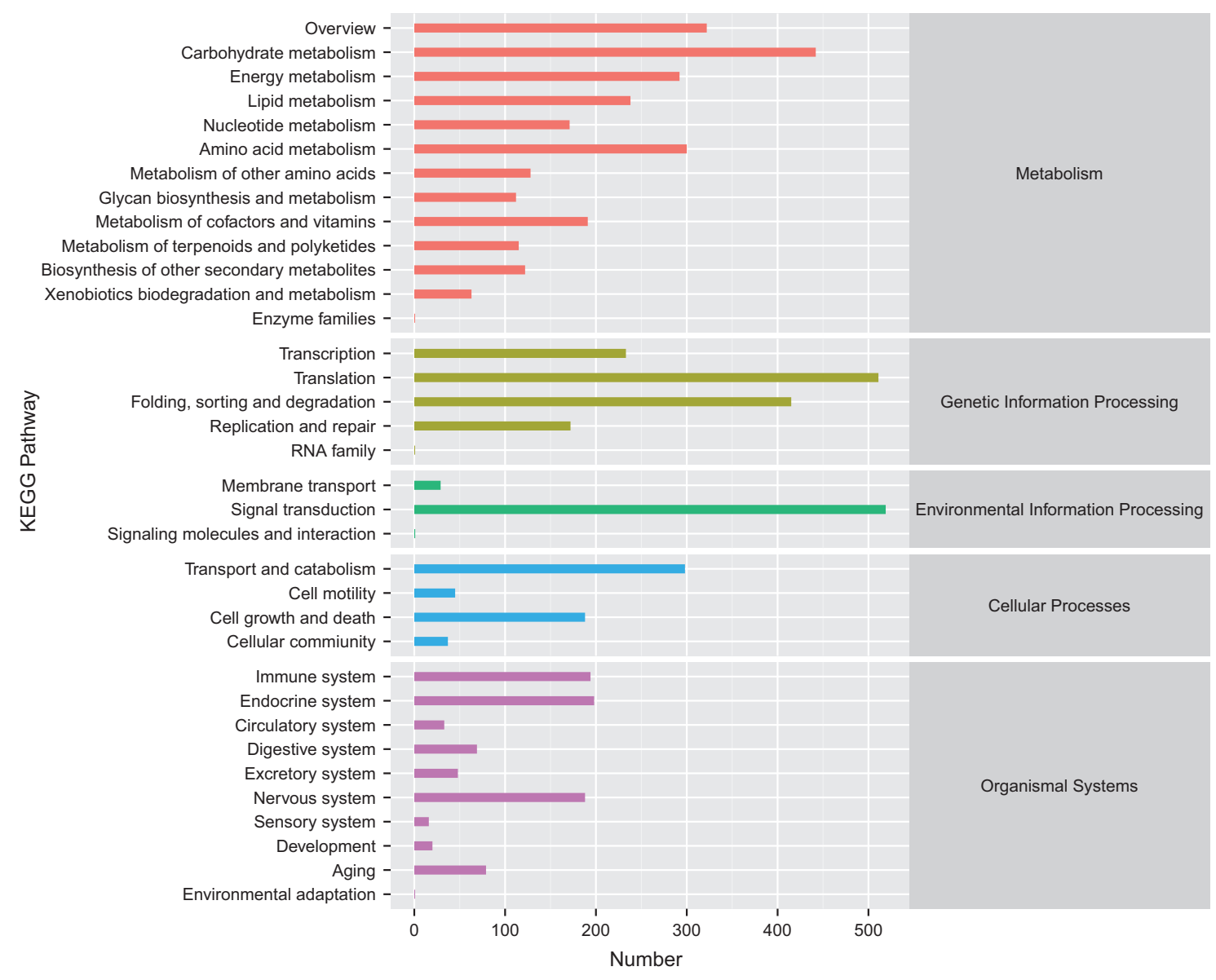

Figure 5. KEGG pathway annotations of Camellia sinensis transcriptome. Bars represent the numbers of unigenes clustered into KEGG Orthology (KO) hierarchies. "Signal transduction", "translation" and "carbohydrate metabolism" were the most abundant categories in KO hierarchies. Certain category as "transport and catabolism" was highly related to experimental conditions.

\begin{tabular}{|l|l|l|}
\hline Database & Number & Percentage\% \\
\hline NR & 40,894 & 58.85 \\
\hline GO & 23,260 & 33.47 \\
\hline KEGG & 6,212 & 8.94 \\
\hline
\end{tabular}

Table 5. Summary of annotations on different databases.

Functional annotations were obtained by sequence based alignments performed by blast search (BLASTx) against the non-redundant protein database $(\mathrm{Nr})$. The $\mathrm{Nr}$ species distribution and e-value distribution (Fig. 3 ) revealed that $55.24 \%$ of unigenes with hits had a strong homology with the sequences available in the $\mathrm{Nr}$ protein database $\left(\mathrm{e}\right.$-value $<\mathrm{e}^{-45}$ ). The distribution of $\mathrm{Nr}$ species was revealed that the majority of Camellia sinensis unigenes showed the highest homology with Actinidia chinensis var. chinensis (52.05\%), then Vitis vinifera (5.49\%), Quercus suber (4.10\%), Camellia sinensis (2.69\%), Juglans regia (1.47\%), Olea europaea var. sylvestris (1.24\%), Coffea canephora (1.19\%), Nelumbo nucifera (1.02\%), Hevea brasiliensis (0.98\%), Theobroma cacao (0.94\%), Sesamum indicum (0.77\%), and others (28.05\%). Because of limited $\mathrm{Nr}$ annotations of Camellia sinensis, only $2.69 \%$ of the unigenes had $\mathrm{Nr}$ annotations against Camellia sinensis. However, 93.19\% (64756 out of 69 488) of all unigenes could mapped on newly published tea genome database using tophit software. Unigenes unable to mapped on tea genome database and predicted fusion genes information were offered in appendix (Supplementary Table 1 and Supplementary Table 2). The major distribution of GO annotations was listed in Fig. 4, based on the Blast2GO software analysis. GO database includes three main categories: biological process, cellular 
component and molecular function. Within the biological process category, "cellular process", "metabolic process", and "single-organism process" were the most abundant sub-categories. In cellular component category, the predominant portion of unigenes represented "membrane", "cell" and "cell part" followed by "membrane part" and "organelle". Under the molecular function category, "catalytic activity" and "binding" sub-categories were the major proportions of unigenes. The distribution of KEGG pathways annotations was shown in Fig. 5. Sub-categories as "signal transduction", "translation" and "carbohydrate metabolism" were the most abundant categories in KO hierarchies. Besides, certain category as "transport and catabolism" was highly related to experimental conditions. The summary of databases annotation was listed in Table 5.

\section{References}

1. Ruan, J. Y. \& Wong, M. H. Accumulation of fluoride and aluminium related to different varieties of tea plant. Environ Geochem Hlth 23, 53-63 (2001).

2. Shu, W. S., Zhang, Z. Q., Lan, C. Y. \& Wong, M. H. Fluoride and aluminium concentrations of tea plants and tea products from Sichuan Province, PR China. Chemosphere 52, 1475-1482 (2003).

3. Lu, Y., Guo, W. F. \& Yang, X. Q. Fluoride content in tea and its relationship with tea quality. J Agr Food Chem 52, 4472-4476 (2004).

4. Fung, K. F., Zhang, Z. Q., Wong, J. W. C. \& Wong, M. H. Fluoride contents in tea and soil from tea plantations and the release of fluoride into tea liquor during infusion. Environ Pollut 104, 197-205 (1999).

5. Malinowska, E., Inkielewicz, I., Czarnowski, W. \& Szefer, P. Assessment of fluoride concentration and daily intake by human from tea and herbal infusions. Food Chem Toxicol 46, 1055-1061 (2008).

6. Cao, J. et al. Brick tea fluoride as a main source of adult fluorosis. Food Chem Toxicol 41, 535-542 (2003).

7. Webbpepl., M. M. \& Bradley, W. G. Endemic Fluorosis with Neurological Complications in a Hampshire Man. J Neurol Neurosur Ps 29, 577-583 (1966).

8. Ruan, J. Y., Ma, L. F., Shi, Y. Z. \& Han, W. Y. Uptake of fluoride by tea plant (Camellia sinensis L) and the impact of aluminium. $J$ Sci Food Agr 83, 1342-1348 (2003)

9. Nagata, T., Hayatsu, M. \& Kosuge, N. Aluminium kinetics in the tea plant using ${ }^{27} \mathrm{Al}$ and ${ }^{19} \mathrm{~F}$ NMR. Phytochemistry 32, 771-775 (1993)

10. Zhang, X. C. et al. $\mathrm{Ca}^{2+}$ and $\mathrm{CaM}$ are involved in $\mathrm{Al}^{3+}$ pretreatment-promoted fluoride accumulation in tea plants (Camellia sinesis L.). Plant Physiol Bioch 96, 288-295 (2015).

11. Ruan, J. Y., Ma, L. F., Shi, Y. Z. \& Han, W. Y. The impact of pH and calcium on the uptake of fluoride by tea plants (Camellia sinensis L.). Ann Bot-London 93, 97-105 (2004).

12. Zhang, X. C., Gao, H. J., Zhang, Z. Z. \& Wan, X. C. Influences of different ion channel inhibitors on the absorption of fluoride in tea plants (Camellia sinesis L.). Plant Growth Regul 69, 99-106 (2013).

13. Jain, M. Next-generation sequencing technologies for gene expression profiling in plants. Brief Funct Genomics 11, 63-70 (2012).

14. Wang, Z., Gerstein, M. \& Snyder, M. RNA-Seq: a revolutionary tool for transcriptomics. Nat Rev Genet 10, 57-63 (2009).

15. Martin, J. A. \& Wang, Z. Next-generation transcriptome assembly. Nat Rev Genet 12, 671-682 (2011).

16. Li, Q. S. et al. Effect of fluoride treatment on gene expression in tea plant (Camellia sinensis). Sci Rep 7 (2017).

17. Stevens, D. P., Mclaughlin, M. J. \& Alston, A. M. Limitations of Acid Digestion Techniques for the Determination of Fluoride in Plant-Material. Commun Soil Sci Plan 26, 1823-1842 (1995).

18. Martin, M. Cutadapt removes adapter sequences from high-throughput sequencing reads. EMBnet J 17, 10-12 (2011).

19. Grabherr, M. G. et al. Full-length transcriptome assembly from RNA-Seq data without a reference genome. Nat Biotechnol 29, 644-652 (2011).

20. Conesa, A. et al. Blast2GO: a universal tool for annotation, visualization and analysis in functional genomics researchBioinformatics 21, 3674-3676 (2005).

\section{Data Citations}

1. NCBI Sequence Read Archive SRP120449 (2017).

2. GenBank GGEB00000000.1 (2017).

\section{Acknowledgements}

The authors appreciate the National Natural Science Foundation of China for financial support to this work (Project No. 31170643).

\section{Author Contributions}

L.Q.S. mainly operated the experiments and prepared the manuscript, including de novo assembly, annotations, alignments and analysis. L.X.M., Q.R.Y., S.E.H. and L.X.M. prepared the samples and basic analysis. L.J.L. interpreted the results. J.H.Y. interpreted the results. Z.X.Q. interpreted the results. L.Y.R. designed the study and prepared the manuscript. All the authors read the final version of the manuscript.

\section{Additional information}

Competing interests: The authors declare no competing financial interests.

How to cite this article: Li, Q.S. et al. De novo transcriptome assembly of fluorine accumulator tea plant Camellia sinensis with fluoride treatments. Sci. Data. 5:180194 doi: 10.1038/sdata.2018.194 (2018).

Publisher's note: Springer Nature remains neutral with regard to jurisdictional claims in published maps and institutional affiliations. 
(c) Open Access This article is licensed under a Creative Commons Attribution 4.0 International License, which permits use, sharing, adaptation, distribution and reproduction in any medium or format, as long as you give appropriate credit to the original author(s) and the source, provide a link to the Creative Commons license, and indicate if changes were made. The images or other third party material in this article are included in the article's Creative Commons license, unless indicated otherwise in a credit line to the material. If material is not included in the article's Creative Commons license and your intended use is not permitted by statutory regulation or exceeds the permitted use, you will need to obtain permission directly from the copyright holder. To view a copy of this license, visit http://creativecommons. org/licenses/by/4.0/

The Creative Commons Public Domain Dedication waiver http://creativecommons.org/publicdomain/ zero/1.0/ applies to the metadata files made available in this article.

(C) The Author(s) 2018 